moreover, all objective evidence of adenoid growth had disappeared. Such an improvement could not have been effected without constant care and attention on the part of the highly trained nurse who carried out the treatment.

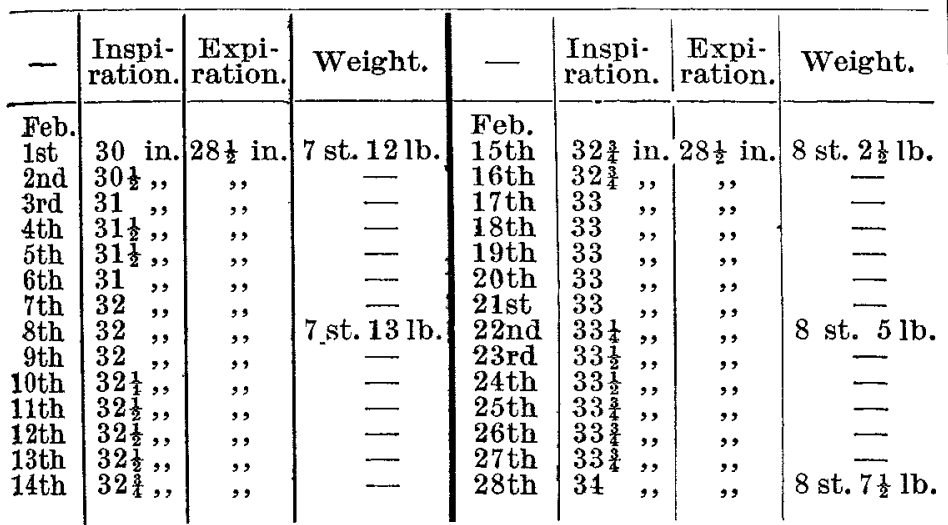

In $1896^{4}$ and subsequently $I$ published several papers on the importance of improving the respiratory capacity of feeble childron, and particularly those who were the subjects of adenoid hypertrophy with or without operation, and to $\mathrm{my}$ surprise $\mathrm{my}$ suggestions met with violent opposition. Sir Felix Semon, the then recognised authority on laryngology, devoted three and a half columins of a lecture, which was published in the British Medical Iournal, ${ }^{5}$ to show that my views on the supposed benefits to be derived from respiratory exercises were ridiculous. To give an idea of the antagonism that the employment of breathing exercises aroused, I quote a few lines from the lecture of this distinguished surgeon "Well, gentlemen, I may be an incurable sceptic, but I have no hesitation in telling vou that I do not believe for a moment that a single child which has got well-marked adenoids has been, or ever will be, cured by breathing cxercises, all reports to the contrary notwithstanding. I mean no disrespect to Mr. Arbuthnot Lane, bit I cannot help saying the whole idea seems to me preposterous"; and again "If it should be called unscientific to say plainly that the rationale of his treatment was a mystery to them, I, for one, miust plead guilty to the soft impeachment. How a genuine lymphoid hypertrophy can ever be expected to be dispersed by breathing exercises completely passes my understanding.'

It would be interesting to compare the views Sir Felix Semon then enunciated on the value of respiratory exercises with those now held by laryngologists, by medical men generally, and even by school teachers and the better educated part of the public. It was not till later that I realised the important influence that intestinal auto-intoxication and chronic intestinal stasis exert upon the respiratory and other functions of the body and how far they are responsible for the development of diseases.

In $1902 \mathrm{I}$ opened a discussion ${ }^{6}$ on the subject at a meeting of the British Medical Association in Manchester, when there was much difference of opinion though the ideas which were expressed by the several speakers, notably by Dr. Harry Campbell, showed that a change of view was taking place with resard to the mechanics and affections of the nasopharynx.

Stasis as the Chief C'ause of Lowered Vitality.

Intestinal stasis develops at an early period in the lifetime of the child. While the infant wears napkins it passes its motion when the bowel recognises the desire to evacuate it. When the napkin is discarded the child is taught to retain the products of 24 hours' digestion in the large bowel, with the result that the

'Some Experiences in the Surgical Out-patients' Room of a Children's Hospital, Clinical Journal, 1896 .

Local Treatment of the Upper Air-passages, Brit. Med. Jour., Nov. 2nd, 1901 .

Respiratory Exercises Med. Jour., Sept. 6 th, 1902 . pelvic colon elongates and secondary changes ensue. Sooner or later the contents of the small intestine become infected by organisms and the food-supply is contaminated. This results in a poisoning of all the tissues and organs of the body, rendering them unable to perform their functions in a norrual manner and reducing their capacity to resist the inroad of micro-organisms. The observation of a large number of delicate children shows that in them thoracic respiration is in abeyance, and that a tape encircling the chest undergoes no variation whatever during respiration. The tissue in the infant in which the earliest evidence of infection by organisms is observed is the Jymphoid tissue in the naso-pharynx. Later in life the evidences of lowered resisting power are shown in an infection of the periodontal membrane to which the name of pyorrhoea has been given. Both these conditions, which are secondary to stasis, are regarded by many as diseases àppearing spon taneously and being themselves causes of stasis and its results. As age advances the amount of energy which can be expended in effecting thoracic respiration diminishes, and the chest and dorsal spine assume the curves that one associates with that time of life. Perhaps most of this is due to the fact that stasis increases with age, and that it is the prime factor in producing disease and death. Again, a great deal of defective thoracic respiration is due to habit, the individual neglecting to keep his chest working efficiently. Besides being very deforming it serves to diminish the oxygenation of the blood and to hasten degenerative processes throughout the body.

A recognition of the facts to which I have called attention in this paper must impress the reader with the importance to the individual of keeping the function of thoracic respiration in an efficient condition, even though little consideration is given to the state of the muscular system generally; also that chronic intestinal stasis, that dread accompaniment of civilisation, should be met by every possible means if the tissues of the body are to be kept in the best possible condition.

\section{THE RATIONALE OF THE WASSERMANN REACTION.}

An Abridged Account of a Paper Read Before the Dermatological Section of the Royal Society of Medicine on Oct. 20th, 1921,

Bx J. E. R. MoDONAGH, F. R.C.S. ENG., SURGFON, LONDON LOCK HOSPITAL.

Thovgh the Wassermann reaction (W.R.) has been extensively employed since 1907, it cannot be said that much progress has been made in unravelling its modus operandi. Some have laid great stress upon the possible interpretations of a positive and negative reaction, but those with a large clinical experience are coming to the conclusion, that a negative reaction signifies nothing, and that a positive reaction means no more than that the patient has had syphilis. It is now being recognised that the reaction can be used, neither as a regulator of treatment nor as a test of cure, and that a positive reaction does not necessarily signify that the disease is active and that the patient requires treatment. Though the experimental work about to be described will form sufficient proof of the statements just enunciated, the main object of this paper is to detail as far as is possible the changes undergone by the protein particles in syphilis, and to throw more light on certain problems which so far have remained unsolved. Before doing this it will be necessary to consider the hæmolytic system, the foundation of all complement-fixation tests, and to point out the relationship it bears to the first part of the W.R.

\section{Homolytic System.}

An immune serum plus complement will cause red blood corpuscles to give up their hæmoglobin, and 
produce what is called hxmolysis. If the serum immunised against the red blood corpuscles, and known as amboceptor, is not inactivated there is no need to employ the fresh serum of another animal, which receives the name of complement. Inactivation causes equal-sized protein particles to agglomerate partially, an action which always leads to a reduction of their Brownian movement, and may lead to a precipitation of some of the clumps formed. In the presence of antigen-that is to say, the substance with which the immunisation is carried out-the immune serum when used fresh and unheated will undergo similar changes, only more slowly, which is likewise the case when the serum is heated and complement is used. While these changes are taking place the surface-tension of the liquid medium is diminished, with the result that the red blood corpuscles give up their hæmoglobin. A specific amboceptor is not essential, because a simple negatively or positively charged colloid will take its place. Either colloidal silicic acid or colloidal aluminium hydroxide will replace the amboceptor. If the two are used together no hæmolysis results, because the iso-electric point is reached. There will also be no hæmolysis if one of the colloids is allowed to interact with the complement some time before the red blood corpuscles are added, because precipitation is the final stage of adsorption, agglomeration, \&c., and when precipitation is complete, the normal surface-tension of the liquid medium becomes restored; consequently the added red blood corpuscles simply fall by their own weight to the bottom of the tube. The fresh serum of a guinea-pig is employed for the complement. In such a serum the protein particles are uniform in size and show vigorous Brownian movement. With colloidal silicic acid the particles decrease in number and rapidly form clumps, which finally become precipitated. During the stage of spontaneous condensation brought about by an increased positive charge, which in turn is produced on the surface of the particles by the non-metallic condenser, there occurs a diminution of the surface-tension, which causes hæmolysis of red blood corpuscles, if the latter are added before the surface-tension has rectified itself. Condensation leads to precipitation, which rights the surface-tension. The metallic conductor (aluminium hydroxide) causes the particles to increase in number and size and then to form small agglomerations. Condensation and final precipitation is the result, though the changes are slower in occurring. The metal causes condensation because the protein particles undergo a change to compensate for the dissipation of electrons and for the loss of certain electrolytes, while the non-metal causes condensation because from the start it leads to a conservation of the negative electricity. It is clear that hæmolysis is a surface-tension phenomenon, and that complement represents the normal electrification of the surface of the protein particles. Complex colloidal metals and non-metals will not act as amboceptor, because their action on the surface of the protein particles penetrates to the mass, and when this occurs precipitation is too rapid to register an alteration in surface-tension.

First Part of the Wassermann Reaction.

This is akin to the non-specific hæmolytic system, in which the protein particles constituting the complement, are precipitated before the red blood corpuscles are added. The patient's serum altered by inactivation and by the disease, adsorbs the antigen and tries to regain its normal state of emulsion at the expense of the complement. Failure to do so results in precipitation with consequent destruction of the complement, hence the amboceptor and red blood corpuscles, when they are added, also become precipitated-a positive W.R. A multitude of substances will act as antigen, and all capable of so acting have a common property in that they lower the surface-tension of the liquid medium in which the patient's protein particles are in true emulsion, and cause agglomeration and precipitation of the particles themselves.
Production of a P'ositive Complement-Fixation Test in Vino.

If a single sub-lothal dose of an unprotected metal $(\mathrm{Al}>\mathrm{Zn}>\mathrm{Bi}>\mathrm{Hg}>\mathrm{Fe}>\mathrm{Cu}>\mathrm{Ag})$ in the colloidal state is injected intravenously into a rabbit it makes the serum give a positive complement-fixation test (C.F.T.). Under the ultra-microscope the particles in such a serum are increased in number and a few are increased in size. The picture given resembles that of an carly syphilitic serum, that of a serum to which a trace of alkali has been added, and that obtained at the negative pole when a current is passed through a serum film. If a lethal dose is injected the C.F.T. may be positive, nerative, or anti-complementary, the result being largely influenced by the particular metal. There is a diminution in the number of the particles, a marked increase in size and clumping with actual precipitation. A similar picture is given by certain late syphilitic serums. If several injections of small doses are prescribed the serum gives a necrative reaction, which usually becomes anti-complementary when too many are made; this is exactly what may happen in an early case of syphilis over-treated with arseno-benzene. Furthermore. the ultra-microscopic pictures obtained in both are identical-namely, marked diminution in the number of the particles, a few giant particles and clumps which evince a ready inclination to become precipitated.

If a single sub-lethal dose of a corresponding nonmetal (belonging to the sulphur group of elements $\mathbf{S}, \mathbf{S c}, \& \mathrm{Te}$ ) is injected, the serum remains negative. If a lethal dose is injected the serum gives a positive C.F.T. and an ultra-microscopic picture similar to that obtained when a serum is treated with an acid, and to the picture witnessed at the positive pole when a current is first passed through a serum film. The particles are diminished in number and many agglomerations are formed, which in some instances are precipitated in masses. If several small doses are injected the serum becomes strongly positive with some preparations and anti-complementary with others, and the ultra-microscopic picture obtained is indistinguishable from that given by certain late syphilitic serums. Furthermore, the ultra-microscopic picture cannot be differentiated from that obtained with a serum changed by a metal, by a serum treated with an alkali, and by a serum at the negative pole during the passage of an electric current. The sequelæ of injecting a metal run, I believe, as follows. When the dose is sub-lethal the conductor effect of the metal causes the protein particles to discharge some of their electrons in the form of both electricity and heat. This would tend to increase the positive charge on their surface, a state of affairs which is incompatible with life. The amphoteric nature of the protein comes to the rescue and the "baseness" of the particles in increased.

This is the phenomenon of spontaneous condensation.' Such a change makes the particles adsorb antigen and they readily go for complement with the hope of extracting therefrom the negative electricity they themselves have dissipated. This results in agglomeration and precipitation of all three and consequently a positive C.F.T. When a lethal dose is employed the discharge of negative electricity and increase of " baseness" may so affect the surface and mass as to render the particles incapable of adsorbing other particles, or as to augment their desire to recover their normal state to such a degree, that they are able completely to precipitate the complement particles without the assistance of the antigen, and give what is called an anti-complementary reaction. An anti-complementary reaction is the half-way house between a strong positive reaction and a negative reaction, because the C.F.T., like all colloidal reactions, is of a cyclical nature. When several small doses are injected the particles become dispersed and go into true solution, in which state they no longer act as colloids. Conversion into the molecular-dispersoid state is possible with a liquid-in-liquid colloidal system, 
to which protein belongs, but it is a forced and not a spontaneous process.

On the other hand, a non-metal, acting as a condenser, at first diminishes the electronic activity of the protein particles, no electrons being discharged. When a lethal dose and several small doses are prescribed, the conservation of electrons, with the resulting increase of hydrogen on the surface, cause the particles to increase their " baseness." Such a step leads to an increased avidity for electrons, which the complement added cannot satisfy, consequently a positive C.F.T. is obtained. If my reasoning is correct the injection of a non-metal or condenser should return a positive reaction produced by a metal or conductor to a negative reaction, and cause the serum to give an ultra-microscopic picture indistinguishable from the normal. Not only is this what happens but the converse is also true. Though the reaction may be reduced to negative if previously positive, or to positive if previously negative, when a single injection of a metal is administered after several injections of a non-metal and vice versâ the ultra-microscopic pictures remain unaltered. This is likewise the case in late syphilis, and shows that once the particles have been accustomed, so to speak, to accommodate themselves to the altered conditions, they continue to perpetuate the changes, irrespective of the drugs prescribed. Consequently one cannot surmise from a given reaction in syphilis how the causative organism is behaving.

Effect of Metals and Non-IIetals on Syphilitic Serums.

In early syphilis metals first increase the positivity of the C.F.T. because the initial stage of dispersion is accompanied by marked electronic activity. In the late stage of dispersion the reaction becomes negative, and occasionally the injection of a non-metal will re-convert it into a positive. Non-metals alone cause an immediate diminution of the positivity with an aggravation of the clinical signs, but their continued administration leads to a degree of positive reaction, which can be reduced only by the employment of metals. In late syphilis, if the reaction is negative to start with, a non-metal acts as a better provocateur of a positive reaction than a metal. If positive to start with, a non-metal will render the C.F.T. temporarily negative quicker than will a metal.

Changes Undergone by the Serum in Syphilis.

The protein particles undergo three main changes: (1) increase in number ; (2) surface change ; (3) mass change.

Increase in Number.-This change is most noticeable in early syphilis and can be detected before the C.F.T. is positive, but any manoeuvre which sets in motion the spontaneous process of condensation will cause the same to give a positive reaction. This can be achieved by shaking with insoluble substances, such as barium sulphate, tin oxide, bismuth subnitrate, \&c. Occasionally in late syphilis an increase in number is to be observed, but in such cases the C.F.T. is always negative and does not change into positive on the administration of a non-metal. These particles are albumin particles which always nullify, if in sufficient quantity, a positive reaction given by globulin particles. They are caused by a conversion of lipoidglobulin into albumin, and all the cases I have investigated had a marked degree of hyperpiesis. Whether the hypertension is due primarily to the increased viscosity of the serum or to the reduction in the surface electrification of the protein particles I cannot at present determine. I am strongly of the opinion that the changes in the vessel walls and kidneys are secondary to those in the serum.

Surface Change.- The protein particles in syphilis contain more electrolytes than normal ; they are therefore capable of greater electronic activity. The discharge of electrons-i.e., the oxidising action of the particles - in the form of electricity and heat to overcome the parasites results in a condensation of the particles and in an increase of their " baseness."

As the disease advances and the electronic activity is continued. the particles lose many of their surface electrolytes. This increases their power of adsorption, which in vitro is measured by precipitation; consequently the most positive serums are usually late syphilitic serums. This being the fact at the stage when there are fewer organisms, again supports the view expressed that there is no parallel between the two. When the loss of electrolytes is exactly counterbalanced by the mass change, the lipoid-globulin so formed reaches its iso-electric point. At this point protein is, so to speak, dead and is excreted into the urine and into the general peritoneal cavity. This protein when collected invariably gives a negative C.F.T. Electronic activity resulting in condensation and increase of " baseness" imparts to particles so altered the chemical and physical properties of globulin. A continuation of the same leads to the formation of lipoid-globulin, which in its turn may be converted into albumin. The changes through which protein can pass are likewise cyclical in nature : Albumin $\rightarrow$ globulin $\rightarrow$ lipoid-globulin $\rightarrow$ albumin. Mass Change.-Apart from changes already observed, the mass exhibits an increase of aminogroups in early syphilis and an increase of lipoid material in late syphilis. The former is proved by Van Slykes's estimation of amino-nitrogen, and the latter is suggested by the behaviour of certain compounds on normal protein particles, by ultramicroscopic examinations, and by the effect produced on serums by the passage of electric currents. Lipoidglobulin can be formed at the negative pole and by shaking a serum with a-naphthylamine. Sometimes ringed particles are formed which in turn, on continued passage of the current, become converted into sheafshaped crystalloid bodies, which at present I take to be the glyceryl-esters of the higher fatty acids. Summed up the position is as follows:-

When the increase of electrolytes bears the same ratio to the amino-groups as occurs normally, the C.F.T. is negative. When the electrolytes become dissipated and the protein mass has to undergo changes to compensate for the loss, the C.F.T. is positive, because the adsorptive capacity of the particles is increased with the hope of being able to take from the particles added the electrolytes necessary to restore the balance. When the loss of electrolytes is just balanced by the substantive changes the O.F.T. is negative. When the electrolytes are still further destroyed, the C.F.T. is anti-complementary, because nothing added can restore the balance; in fact, anything added only furthers the precipitation. This stage corresponds to that produced when a normal organ is extracted with alcohol or acetone.

Thus we are now able to visualise the exact action of antigen. In fact, certain protein particles when rendered anti-complementary will serve as the antigen. A W.R. can actually be undertaken with ingredients made from the patient's own blood with the sole addition of some colloidal silicic acid for use as the amboceptor. A serum can be rendered anticomplementary by shaking with naphthalene, $a$-naphthol, and a-naphthylamine. If the serum is filtered, dried, and dissolved in saline, only the one treated with $a$-naphthylamine will act as antigen. $a$-Naphthylamine converts the protein particles into lipoid-globulin, diminishes the surface-tension, and diminishes the viscosity of the liquid medium. Further, it causes marked agglomeration and condensation of the protein particles. In other words, it imparts to the protein particles those characters upon which we have seen the C.F.T. depends. A like degree of agglomeration and condensation occurs normally in the serum of most pregnant women. This explains why at least 10 per cent. of non-syphilitic women when they are pregnant give a positive C.F.T., and why many syphilitic women (except those recently infected) give a negative C.F.T. From the foregoing we can also understand why repeated freezing and thawing, exposure to alterations of atmospheric pressure and to radio-active bodies, and shaking with various nonelectrolytic substances, tend to make a normal serum give a positive or anti-complementary reaction. They make a slightly positive serum more positive 
and a strong positive serum either negative or anticomplementary. Practically speaking, any factor which causes the condensation of the protein particles may make a normal serum, and an early and late syphilitic serum behave as just described. It furthermore renders the protein particles more stable, a phenomenon which accounts for the facts, that a late syphilitic serum after the ingestion of alcohol is apt to give a negative C.F.T.; that the addition of sodium citrate fails to check coagulation; and that shock is prevented from following a second and what would ordinarily have been a lethal dose. The whole story is really that of a combat on the part of the protein particles-one of condensation versus dispersion.

Finally, I think we may conclude that a negative C.F.T. does not exclude syphilis, and that a positive C.F.T. means no more than that presumably the patient has had the disease.

\section{THE \\ SACHS-GEORGI REACTION IN SYPHILIS.}

BY JAMES LAW BROWNLIF, M.D. GLASG., D.P.H., CAMrB.,

ASSISTANT BACTERIOIOGIST, CORPORATION LABORATORY, GLASGOW.

The very interesting contributions by Dr. A. Neave Kingsbury ${ }^{1}$ and Dr. C. C. Okell ${ }^{2}$ to the above subject have prompted me to present the following figures based on a comparative study of 500 serums submitted to the Wassermann (W.R.) and Sachs-Georgi (S.G.) reactions.

Mothod.-The W.R. was performed by Harrison's method, the S.G. in the simplest manner possible. Only one tube was used for each serum tested. The antigen was the same as employed in the W.R.namely, three parts of a suitably diluted alcoholic extract of human heart muscle reinforced with two parts of a 1 per cent. alcoholic solution of cholesterin. The only difference was in the manner of adding the saline. For the W.R. the addition was made rapidly as recommended by Harrison, for the other the addition was made slowly. The opacity of the resultant emulsions varied accordingly. 0.3 c.cm. patient's serum was added to $1 \mathrm{c.cm}$. of antigen and the tube agitated to ensure complete mixing. The tubes were put in the ice-chest and readings were taken at 24 and 48 -hour intervals. For practical purposes it was not found that the longer period produced any appreciable change in the appearance of the tubes, so that towards the end of the series the second reading was discontinued.

The serums used in the S.G. were quite unselected. During the investigation the number of specimens of blood submitted for the W.R. averaged 80 . Considerations of time prevented the performance of both tests upon all each day but, as circumstances allowed, 20 to 40 were taken indiscriminately and tested as indicated above. It will be realised that by this means all circumstances governing the components of each test were exactly comparable. As the question of the use of inactivated as against uninactivated serum appeared to be at issue, 250 were tested with heated and 250 with unheated serum. Analysis of the results obtained in each instance did not provide sufficient data to warrant a definite pronouncement regarding the matter. It was, therefore, decided to combine all the results and present them as a record of a series.

TABLE $\mathrm{I}$.

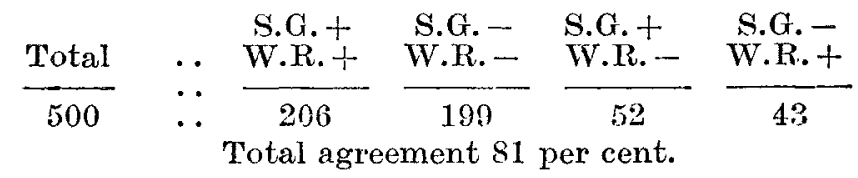

For simplicity of reference and for purposes of comparison I have taken the liberty (which I hereby

1 The LaNCet, Oct. 15th, 1921, p. 799

${ }^{2}$ Ibid., Nov. 5th, 1921 , p. 962 . acknowledge) of substituting my figures in the table so simply and effectively made out by Dr. Okell.

Apart from satisfying myself as to the comparative merits of the tests I was further interested to learn something of the respective values of each in varying clinical stages of syphilis. It must be understood that I was not responsible for the diagnoses. I accepted the statement of the practitioners submitting the specimens. In Table II. I have attempted to show

TABLE II.

\begin{tabular}{|c|c|c|c|c|c|c|}
\hline \multicolumn{2}{|c|}{ Symptoms. } & Total. & S.G. & H.M.§ & $\begin{array}{l}\text { S.G. } \\
\text { per cent. }\end{array}$ & $\begin{array}{c}\text { H.M. } \& \\
\text { per cent. }\end{array}$ \\
\hline O.C.T.* & $\cdots$ & $31\left\{\begin{array}{r}7 \\
11 \\
13\end{array}\right.$ & $\overrightarrow{+}$ & $\begin{array}{c}++ \\
+\end{array}$ & $41 \cdot 9$ & $58 \cdot 1$ \\
\hline Priniary & . & $7 ! \begin{array}{l}1 \\
1\end{array}$ & $\overline{-}$ & $\begin{array}{c}++ \\
+\end{array}$ & $71 \cdot 4$ & $28 \cdot 6$ \\
\hline Secondary & . & $8\left\{\begin{array}{l}1 \\
2 \\
5\end{array}\right.$ & $\bar{t}$ & $\begin{array}{l}++ \\
+ \\
-\end{array}$ & $62 \cdot 5$ & $37 \circ 5$ \\
\hline Tertiary & . & $13 \underbrace{\frac{1}{2}}$ & $\overline{-}$ & $\stackrel{t+}{+}$ & $76 \cdot 9$ & $23 \cdot 1$ \\
\hline C.N.S.S.† & . & $16 \frac{1}{2} \begin{array}{r}3 \\
11\end{array}$ & $\frac{-}{+}$ & $\begin{array}{c}++ \\
+\end{array}$ & $68 \cdot 7$ & $31 \cdot 3$ \\
\hline C.S. $\ddagger \ldots$ & . & $4\left\{\begin{array}{l}\overline{2} \\
2\end{array}\right.$ & $\frac{1}{+}$ & \pm & 50 & 50 \\
\hline Gonorrhœa & . & $8\left\{\begin{array}{l}1 \\
3 \\
4\end{array}\right.$ & $\frac{-}{+}$ & $\begin{array}{c}++ \\
+\end{array}$ & 50 & 50 \\
\hline $\begin{array}{l}\text { Syphilis in } \\
\text { family }\end{array}$ & & $8: \begin{array}{l}2 \\
4 \\
2\end{array}$ & $\frac{-}{+}$ & $\begin{array}{l}++ \\
+\end{array}$ & 25 & 75 \\
\hline
\end{tabular}

* Old case treated. † Central nervous system syphilis. $\S$ Wassermann reaction, Harrison's method.

how the 95 disagreements in the series were related to the specified stage of the disease. It will be seen that the S.G. gave a greater percentage of positive readings in primary, secondary, tertiary, and central nervous system syphilis; the W.R. in old treated cases and familial syphilis; whilst the results balanced in congenital syphilis and in gonorrhoeal cases. Under the conditions of experiment outlined it appeared that, unlike Dr. Okell, with a negative W.R. the S.G. was not so seldom positive as to enable me to confirm his opinion that " where the Sachs-Georgi was used in place of the Wassermann only a small percentage of patients would be unnecessarily submitted to treatment." 2 I had not viewed the S.G. in this light as, judging from most of the clinical histories provided, I came to the conclusion that the S.G. was more delicate, especially in primary and early secondary syphilis. Such a point, however, I would not be inclined to strain as it is based upon a relatively small number of cases. I have no doubt that the more complicated modifications indicated by Dr. Okel were responsible for his excellent percentage agreements, but it appeared of interest to record that satisfactory figures were obtainable in the extremely simple manner indicated. After all, the ideal longed for by every worker in this branch of serology is simplicity, and substitution tests are only attractive the more nearly they approach to that ideal. From a purely practical point of view, one wonders what advantage alternative tests have over the Wassermann reaction. Greater specificity has not yet been proved for them and their introduction into routine work merely serves to cause confusion.

I am indebted to Dr. R. M. Buchanan, city bacteriologist, who afforded me every facility in carrying out the work, and to Miss D. L. Young who assisted me throughout the investigation.

General Practitroners and Midwives.-The Ministry of Health will shortly hold a conference with the County Councils' Association on points arising out of the scale of fees payable to medical practitioners under Section 14 of the Midwives Act, 1918. The London County Council has been invited to send representatives and has decided that the members of its Midwives Acts Committee shall attend. 